\title{
Effect of Psycho-educational Intervention on Burden and Quality of Life Among Family Caregivers of Schizophrenic Patients
}

\author{
Rania Rabie El-Etreby Azza Ibrahim Abdelraof \\ Lecturer of Psychiatric and Mental Health Nursing, Faculty of Nursing-Mansoura University
}

\begin{abstract}
:
Introduction: Schizophrenia is a disturbing and stressful disorder for both the patient and his caregiver. Psychoeducational intervention is believed to efficiently meet the informational needs of families to improve their quality of life when caring for a family member with schizophrenia, thereby reducing the patient's relapse from the disorder. Aim: The study aimed to determine the effect of the psycho- educational intervention on burden and quality of life among caregivers of schizophrenic patients. Methods: A quasi-experimental research design [pretest -posttest] was used in the current study, The subjects consisted of 50 caregivers of hospitalized schizophrenic patients, who were selected according to the inclusion criteria. The study was carried out at the in-patient psychiatric department of the Mansoura University Hospital. The instruments used for data collection were, Sociodemographic and Clinical Data Structured Interview Schedule, The Zarit Burden Interview and Quality of life scale. Results: There was a statistically significant difference in mean scores of the burden and quality of life between pre and post the intervention. Conclusion: Burden and quality of life of caregivers of patients with schizophrenia improved significantly after the psycho-educational intervention. Recommendation: Caregivers of schizophrenic patients should be counseled and encouraged to participate in psycho-educational programs to understand unnecessary behavioral changes and to to improve their burden and quality of life.
\end{abstract}

Keywords: schizophrenia, caregivers, burden, quality of life, psycho-educational intervention

DOI: $10.7176 / \mathrm{JHMN} / 63-09$

Publication date: June $30^{\text {th }} 2019$

\section{Introduction}

Schizophrenia is a severe psychiatric illness, manifested by essential disturbances in thought, perception and emotions. Also, it is one of the most debilitating psychiatric disorders around the world (Abdulkareem, Folorunsho, \& Akinsola., 2009).

Caregiver is the most significant member who provide care for the patient with schizophrenia. About 60 to $85 \%$ of those patients are cared by the family member. A schizophrenic patient generally depends on his family caregiver in doing his everyday routine activities such as, eating, bathing, dressing; taking drugs, and checking up. So, family caregiver can experience high levels of burden, especially when care is provided for longer time, that leads to a negative effect (Rafiyah \& Sutharangsee., 2011).

Several studies had indicated that family caregivers experience social, physical, financial, and psychological problems of caring for patients with psychiatric disorders and often times encounter inappropriate support from the mental health members. Family caregivers who are already challenged with daily problems that influence all parts of their lives (World Federation of Mental Health, 2010, Neena \& kamal., 2010).

The effect of providing care to psychiatric ill patients on the caregivers' quality of life (QoL) is considerable, especially when faced with a severe burden, limited roles and activities, and increased anxiety, depression or psychosomatic symptoms. Moreover, the increase caregiver burden might be related to impaired functioning and increased severity of psychiatric disorder which considers the most impact on caregiver burden and QoL (Hjarthag, Helldin, Karilampi \& Norlander., 2010).

Although, recent improvement in the psycho-pharmacological therapy reduced the need for continuing hospitalization, but the patient caregiver's role remains essential in the treatment course. Some researchers reported that caregivers usually do not have the skills and knowledge to provide care to a patient with schizophrenia, therefore many psycho-educational interventions have been developed to interfere in this situation and teaching coping strategies for the disorder and its consequences (Fallahi, Sheikhona, Rahgouy\& Rahgozar., 2014 \&Yazici, Karabulut, Yildiz \& Baskant., 2016).

Family psychoeducation is effective interventions in treating patients with schizophrenia. Several researches have shown that psychoeducational intervention for families with schizophrenic patients not only improves the social and total functions of the patients but also improves the QoL for both of them. The family psychoeducation is a group of organized techniques depend on the supportive and cognitive behavioral therapy process which focus on the patient and the needs of his family. These techniques also focused on improving patients and families' awareness about psychiatric disorders, coping with the disorders, and communicating and improving problem solving abilities (Pitschel-Walz, Baüml \& Bender 2006).

Psychoeducational interventions challenge to develop the subsequent main beliefs: the illness is a brain disease; the pharmacological therapy is necessary, family participation as a primary rehabilitation factor, ensuring 
sufficient emotional support of the family, seeking to improve patient rehabilitation and reintegration into the social environment. The effects of a psychoeducational program for caregivers have indicated that decreasing the emotional burden on patients' families resulting in improving their self-efficacy and reducing the number of relapses at initial stages of the disorder (Breitborde, Moreno, Mai-Dixon, \& Peterson,., 2011).

Psychiatric nurses have a positive role in patients' care throughout assessment, referral, and successful communication with the secondary service and cooperation with patients' families. Nurses play an important role, especially in three aspects of care; physical care, relapse prevention and psycho-education (Gurney, 2013). Consequently, psychiatric nurse has to provide psycho-education for schizophrenic patients and their families and it is very essential to engage the patient's family in the treatment plan through specific psychotherapeutic strategies. Thus, family psycho-education can be helpful to provide support, education, and guidance (Zaretsky, Rizvi \& Parikh, 2007).

\section{Significance of the study}

There is support that individuals who are well educated are able to preserve a better commitment to the treatment process and have the greatest incentive to expand a better way of life that reduces risk factors. The goals of psychoeducational interventions are given information on psychiatric disorder, improve patients and their families' selfcare skills, and a more meaningful relationship between patients, families and mental health members. It also leads to decrease relapse rate and improved quality of life for patients and families (Gutiérrez-Maldonado \& CaqueoUrízar., 2007 \& North et al., 1998).

\section{Aim of the study:}

The current study aimed to determine the effect of the psycho- educational intervention on burden and quality of life among family caregivers of schizophrenic patients.

\section{Hypothesis}

The psycho-educational intervention has a positive effect on reducing the burden and improving quality of life among family caregivers of schizophrenic patients.

\section{Subjects and Method:-}

Design: A quasi-experimental design (pretest- posttest) was used in this study.

Settings: The study was carried out at the In-Patient Psychiatric Unit of the Mansoura University Hospital, affiliated to the Ministry of Higher Education and Scientific Research.

\section{Subjects:}

The subjects of this study comprised 50 caregivers of hospitalized schizophrenic patients. They were chosen according to the following inclusion criteria: (1) caregivers living with the patient in the same place; (2) the primary caregivers of the patient; (3) able to read and write; (4) did not experience co-morbidity of other psychiatric disorder during the time of the study; (5) caregivers willing to participate in the study; (6) did not care for more than one family member with psychiatric disorder and (7) did not receive any psychiatric treatment or participate in other psychiatric program during the preceding year.

The calculated sample size of the study was 50 by using the following formula at $5 \%$ level of significance and $80 \%$ power:

$\mathrm{N}=(\mathrm{Z} 1-\alpha / 2+\mathrm{Z} 1-\beta)^{2} \sigma 1^{*} \sigma 2 / \delta^{2}$

$\mathrm{Z} 1-\alpha / 2=1.96$

$\mathrm{Z} 1-\beta=0.842$

$\sigma=$ Population SD

$\delta=$ Expected difference to be detected between the sample and population

$\alpha=$ Level of acceptability of a false positive result (level of significance $=0.05$ )

$\beta=$ Level of acceptability of a false negative result $(0.20)$

$\beta=$ power $(0.80)$

The selected paper, (Sharif et al., 2016), is the nearest paper to the current study that apply the effect of the psychoeducational program on the burden in families of patients with schizophenia.

\section{Tools of data collection:}

Tool I- Socio-demographic and Clinical Data Structured Interview Schedule:

It was developed by the researchers to elicit data about the schizophrenic patients and their family caregivers, it includes:

a- Socio- demographic and clinical data of patients including: age, sex, educational level, marital status, occupation, duration of illness, treatment, frequency of hospitalization and psychiatric family history. 
b- Socio- demographic data of caregivers such as, age, sex, degree of relation to the patient, number of family members, marital status, educational level and occupation.

Tool II: The Zarit Burden Interview (ZBI). It was developed by Zarit,et al (1980), and translated into Arabic language by Ali, (2015). It is a valid and reliable tool with Cronbach's alpha $(r)=0.85$. The interview provides a global, unidimensional measure of caregiving burden. 22-item rating scale assessing the burden in health, psychological well-being, finances, social life and relationship with the patient. Every item in the interview is a statement that the caregiver is required to support using a 5-point Likert scale ranging from 0 (Never) to 4 (Nearly Always). Scoring system: o to $20=$ little or no burden; 21 to $40=$ mild to moderate burden; 41 to $60=$ moderate to severe burden; 61 to $88=$ severe burden.

Tool III- Quality of life scale: Arabic version of QOL developed by (World Health Organization, 1997) to evaluate the individual's perceptions about their culture and worth systems, and their personal goals, principles and concerns. It consists of 24 items related to four domains. As well, two items related to the overall QOL and general health facet have been included. The four main domains are: Physical domain 7 items; 3, 4, 10, 15, 16, 17 and, 18. Psychological domain 6 items; 5, 6, 7, 11, 19 and, 26. Social domain; 3 Items; 20, 21 and, 22. And environmental domain; 8 items; $8,9,12,13,14,23,24$ and, 25 . The scoring system for every item is rated on a five-point likert scale and scored from one to five on a response scale. The scores of each domain are measured in a positive direction (i.e., higher scores indicate higher QOL). The mean score for each domain is summed up and calculated in order to convert the domain score into a scaled score of zero to 100 , with a higher score indicating a higher QOL and each domain score is then comparable to the scores used in the original WHOQOL-BRIEF.

\section{Method}

An official consent was obtained from the General Director of Psychiatric Department at Mansoura University Hospital after clarifying the study aim, setting the time for starting and explaining the study process to get their support and cooperation during the time of data collection.

Tool (1) was developed by the researchers after reviewing the related literature. It included sociodemographic and clinical data related to the patients and their caregivers. A pilot study was carried out with $10 \%$ of caregivers of patients with schizophrenia from the in-patient psychiatric department of the Mansoura University Hospital, to test the clarity and applicability of the study tools and to determine the time needed for data collection; those caregivers were excluded from the total study subjects.

Informed approval was obtained from the caregivers before conducting the study. Each caregiver was interviewed individually by the researchers to discuss the purpose of the study, the aim of the group and the content of the intervention.

The researchers started to fill-out the study tools from the caregivers through individual interviewing. This interview took about 25 to 30 minutes. The time of the psycho-educational intervention sessions were coordinated with the caregivers to be suitable for them.

The intervention was implemented for the studied caregivers; they were divided into groups, five to eight caregivers in each group. Each group attended 9 sessions ( 3 sessions /week) and each session lasted for 30-45 minutes. The researchers implemented the intervention for each group in scheduled times and days, to ensure exposure of all caregivers in the groups to the same content and learning experiences. The intervention was implemented through various teaching methods as short lectures, group discussions, brain storming, demonstration re-demonstration, and role-play. The teaching media included power-point presentations, and a handbook.

The researchers started each session with a conclusion about what was given during the preceding session and the objectives of the new one to confirm that they recognize the intervention content, taking into consideration the use of simple language to suit the educational level of the participants. Motivation and reinforcement techniques as praise and recognition were used during the session to enhance participation and learning

The initial part of every session composed of a lecture given by the researchers, and the final part of the same session, composed of a question and answer and time for discussion. Throughout this time, the participants discussed events and problems associated with caregiving and described other ways of dealing with these problems. Throughout the intervention, the participants were educated about the psychiatric disorder, and the associated social and mental health issues. Furthermore, They were trained in different ways to take care of themselves, observe their own emotions, ways to control patient's symptoms and how to improve their coping skills and problem solving techniques.

Immediately after the end of the intervention and after two months follow up, the researchers reassessed the studied subjects using tool II and tool III. The study was carried out through 5 months from March 2018 to July 2018. 


\begin{tabular}{|c|c|c|}
\hline Session & Goals & Session activities \\
\hline First session & $\begin{array}{l}\text { Build a trusting } \\
\text { relationship between the } \\
\text { researchers and the } \\
\text { caregivers. }\end{array}$ & $\begin{array}{l}\text { Outline the program and introduce researchers and caregivers } \\
\text { to each other. } \\
\text { Discuss the consequence of orientation to the patient's } \\
\text { symptoms and behaviours. }\end{array}$ \\
\hline Second session & $\begin{array}{l}\text { Understand the disorder } \\
\text { and its manifestations, } \\
\text { treatments and its } \\
\text { impact on the patients } \\
\text { and their families }\end{array}$ & $\begin{array}{l}\text { Provide explanations of patient's symptoms, behaviors and } \\
\text { their effects on the family. } \\
\text { Discuss the etiology and different treatments. }\end{array}$ \\
\hline Third session & $\begin{array}{l}\text { Acquire skills in dealing } \\
\text { with the patient's } \\
\text { symptoms. }\end{array}$ & $\begin{array}{l}\text { Review the previous session. } \\
\text { Discuss the significance of effective communication skills } \\
\text { between the family and the patients when they have } \\
\text { symptoms. } \\
\text { Demonstrate skills in dealing with patients' symptoms, and } \\
\text { cognitive - behavioural techniques to manage patient } \\
\text { symptoms. } \\
\text { Explore intense feelings towards the patient. }\end{array}$ \\
\hline Fourth session & $\begin{array}{l}\text { Identify the impact of } \\
\text { drugs and compliance. }\end{array}$ & $\begin{array}{l}\text { Review the previous session. } \\
\text { Discuss the positive and negative effects of the drugs and its } \\
\text { side effects. } \\
\text { Focus on the significance of drug compliance. }\end{array}$ \\
\hline Fifth session & $\begin{array}{l}\text { Understand the warning } \\
\text { signs of relapse and its } \\
\text { prevention. }\end{array}$ & $\begin{array}{l}\text { Review the previous session. } \\
\text { Discuss the warning signs of relapse. } \\
\text { Explain the role of the family in preventing relapse. }\end{array}$ \\
\hline Sixth session & $\begin{array}{l}\text { Recognize efficient ways } \\
\text { to express feelings and } \\
\text { enhance communication } \\
\text { skills. }\end{array}$ & $\begin{array}{l}\text { Review the previous session. } \\
\text { Discuss expression of feelings and the emotional environment } \\
\text { in the family. } \\
\text { Discuss ways to deal with the negative feelings of the patient }\end{array}$ \\
\hline Seventh session & $\begin{array}{l}\text { Recognize coping } \\
\text { strategies to take care of } \\
\text { themselves, and problem } \\
\text { solving technique. }\end{array}$ & $\begin{array}{l}\text { Review the previous session. } \\
\text { Provide the caregivers with instruction about coping } \\
\text { strategies and problem solving skills. }\end{array}$ \\
\hline Eighth session & $\begin{array}{l}\text { Educate caregivers to } \\
\text { stress management } \\
\text { techniques }\end{array}$ & $\begin{array}{l}\text { Review the previous session. } \\
\text { Discuss the importance of stress management techniques. } \\
\text { Discuss ways to reduce stress. } \\
\text { Practicing relaxation methods during the session. }\end{array}$ \\
\hline Ninth session & Terminate the sessions. & $\begin{array}{l}\text { Evaluation of the program and termination achieved through: } \\
\text { Summary \& feedback about the previous sessions. } \\
\text { - Expressing their feelings, reaction toward the intervention. }\end{array}$ \\
\hline
\end{tabular}

\section{Ethical consideration}

An approval was obtained from the Research Ethical Committee of the Faculty of Nursing, Mansoura University. Informed consent was obtained from the participants to voluntarily participate in the study after explaining of the research aim. Caregivers were reassured that they have the right to withdraw from the study at any stage without any negative consequences. They were reassured that the collected data would be treated with confidentiality and it would be used only for the purpose of the research. Caregivers' privacy was respected.

\section{Statistical analysis:}

Data were analyzed with SPSS version 24. The normality of data was first tested with one-sample KolmogorovSmirnov test. Qualitative data were described using numbers and percent. Continuous variables were presented as mean $\pm \mathrm{SD}$ (standard deviation) for parametric data. The two groups were compared with Student $t$ test (parametric data). Analysis Of Variance (ANOVA test) used for comparison of means of more than two groups (parametric data). For any of the used tests, results were considered as statistically significant if $\mathrm{p}$ value $\leq 0.050$. 
Results:

Table (2): Socio-demographic characteristics of the studied patients:

Age mean+SD (33.46+14.93)

\begin{tabular}{l|l|}
\hline Socio-demographic characteristic \\
\hline Sex \\
\hline Male \\
\hline Female \\
\hline
\end{tabular}

Number $\%$

\begin{tabular}{|l|l|}
\hline 14 & 28.0 \\
\hline 36 & 72.0 \\
\hline
\end{tabular}

\section{Educational Level}

\begin{tabular}{l|l|l}
\hline Illiterate & 8 & 16.0 \\
\hline R \&W & 4 & 8.0 \\
\hline Primary & 8 & 16.0 \\
\hline Prep & 8 & 16.0 \\
\hline Secondary & 4 & 8.0 \\
\hline Diplome & 15 & 30.0 \\
\hline College & 3 & 6.0
\end{tabular}

\section{Marital Status}

Single

Married

Divorced

Widow

\begin{tabular}{|l|l|}
\hline 19 & 38.0 \\
\hline 17 & 34.0 \\
\hline 9 & 18.0 \\
\hline 5 & 10.0 \\
\hline
\end{tabular}

\section{Occupation}

Not working

Student

Employed

Worker

Housewife

Farmer

Retirement

\begin{tabular}{|l|l|}
\hline 11 & 22.0 \\
\hline 3 & 6.0 \\
\hline 2 & 4.0 \\
\hline 10 & 20.0 \\
\hline 19 & 38.0 \\
\hline 4 & 8.0 \\
\hline 1 & 2.0 \\
\hline
\end{tabular}

\section{Residence}

\begin{tabular}{|l|l|l|}
\hline Urban & 20 & 40.0 \\
\hline Rural & 30 & 60.0 \\
\hline \multicolumn{1}{|l|}{} & \\
\hline Level of income & 29 & 58.0 \\
\hline Not enough & 21 & 42.0 \\
\hline Enough & & \\
\hline & 8 & 16.0 \\
\hline Admission number & 19 & 38.0 \\
\hline $1-4$ & 23 & 46.0 \\
\hline$>4-6$ & & \\
\hline More than 6 & 34 & 68.0 \\
\hline Smoking & 16 & 32.0 \\
\hline NO & \\
\hline Yes & & \\
\hline
\end{tabular}




\begin{tabular}{|l|l|l|}
\hline Socio-demographic characteristic & Number & $\%$ \\
\hline Substance abuse & 38 & 76.0 \\
\hline No & 12 & 24.0 \\
\hline Yes & & \\
\hline & 30 & 60.0 \\
\hline Family history & 20 & 40.0 \\
\hline No & & \\
\hline Yes & 3 & 6.0 \\
\hline & 10 & 20.0 \\
\hline Duration of disease & 15 & 30.0 \\
\hline Less than 1 year & 22 & 44.0 \\
\hline 1-less than 5 & \\
\hline 5-less than 10 & & \\
\hline +10 & & \\
\hline
\end{tabular}

Table (2): Shows socio-demographic characteristics of the studied patients and it appears from the table that, $(16.0 \%)$ were illiterate while (30\%) had a diplome. Regarding marital status, it represented that (38\%) were single while $(34 \%)$ were married. Concerning occupation, it was found that $(22 \%)$ were not working and $(38 \%)$ were housewives and (20\%) were workers. Regarding place of residence, $(60 \%)$ were from rural areas while $(40 \%)$ of them were from urban areas, and $58 \%$ of the study sample didn't have enough money. Regarding admission number, (46\%) of the studied patients were admitted to the psychiatric hospital more than six times. Regarding family history of mental illness, it was found that $(40 \%)$ had positive family history of psychiatric disorder. Concerning the duration of the psychiatric disorder and treatment, $(30 \%)$ of the studied patients have a duration of the disorder and treatment ranged from five to less than ten years, but (44\%) of studied patients have a duration of the disorder and treatment more than ten years.

Table (3): Socio-demographic characteristics of the studied caregivers $(\mathrm{n}=50)$ :

Age: mean + SD $(41.72 \pm 11.17)$

\begin{tabular}{|l|l|l|}
\hline Socio-demographic characteristic & Number & $\%$ \\
\hline Sex & 14 & 28.0 \\
\hline Male & 36 & 72.0 \\
\hline Female & \multicolumn{2}{l|}{} \\
\hline & 10 & 20.0 \\
\hline Educational Level & 3 & 6.0 \\
\hline R \&W & 14 & 28.0 \\
\hline Primary & 2 & 4.0 \\
\hline Prep & 17 & 34.0 \\
\hline Secondary & 4 & 8.0 \\
\hline Diplome & & \\
\hline College & & \\
\hline & 7 & 14.0 \\
\hline Marital Status & 35 & 70.0 \\
\hline Single & 4 & 8.0 \\
\hline Married & 4 & 8.0 \\
\hline Divorced & & \\
\hline Widow & & 8.0 \\
\hline & 4 & 20.0 \\
\hline Occupation & 10 & 68.0 \\
\hline Employed & 34 & \\
\hline Worker & & \\
\hline Housewife & & \\
\hline
\end{tabular}




\begin{tabular}{|c|c|c|}
\hline Socio-demographic characteristic & Number & $\%$ \\
\hline Farmer & 2 & 4.0 \\
\hline \multicolumn{3}{|l|}{ Degree of relatives } \\
\hline Mother & 24 & 48.0 \\
\hline Father & 6 & 12.0 \\
\hline Partner & 4 & 8.0 \\
\hline Sister and brother & 9 & 18.0 \\
\hline Daughter & 7 & 14.0 \\
\hline \multicolumn{3}{|l|}{ Number of family members } \\
\hline $1-4$ & 7 & 14.0 \\
\hline $5-8$ & 25 & 50.0 \\
\hline above8 & 18 & 36.0 \\
\hline \multicolumn{3}{|l|}{ Psychiatric family history } \\
\hline No & 27 & 54.0 \\
\hline Yes & 23 & 46.0 \\
\hline \multicolumn{3}{|l|}{ Residence } \\
\hline Urban & 20 & 40.0 \\
\hline Rural & 30 & 60.0 \\
\hline \multicolumn{3}{|l|}{ Level of income } \\
\hline Not enough & 31 & 62.0 \\
\hline Enough & 19 & 38.0 \\
\hline \multicolumn{3}{|l|}{ Chronic Physical illness } \\
\hline $\mathrm{NO}$ & 36 & 72.0 \\
\hline Yes & 14 & 28.0 \\
\hline
\end{tabular}

Table (3): shows socio-demographic characteristics of the studied caregivers and it appears from the table that, $(72.0 \%)$ were females and $(28.0 \%)$ were males. Regarding the educational level, $(34.0 \%)$ had diplome. Regarding marital status, $(14.0 \%)$ were single while $(70.0 \%)$ were married. Concerning occupation, it was found that $(68.0 \%)$ were housewives and $(20.0 \%)$ were workers. Regarding place of residence, $(60.0 \%)$ were from rural areas while $(40.0 \%)$ of them were from urban areas. $(62.0 \%)$ of the studied subjects didn't have enough income. In relation to the number of family members; it represented that $(50 \%)$ of the studied caregivers' have five to eight members. Moreover, $(46 \%)$ of the studied family caregivers had psychiatric history. Concerning chronic physical illness, it represented that (28\%) of the studied family caregivers had a chronic physical illness.

Table (4): Burden mean score of the studied caregivers before and after the psycho-educational intervention

\begin{tabular}{|c|c|c|}
\hline Burden scale & Mean & ANOVA test \\
\hline Burden pre & $74.32+6.07$ & \multirow{3}{*}{$\mathrm{F}=19.400 \quad \mathrm{P}=<.001$} \\
\hline Burden post (immediately) & $54.94+14.92$ & \\
\hline Burden follow (2 month) & $59.23 \pm 8.87$ & \\
\hline
\end{tabular}

Table (4): The mean score of the studied caregivers pre-intervention was slightly higher (74.32+6.07).

Immediately post intervention, the mean score for the studied caregivers decreased (i.e. improvement) compared to pre intervention $(54.94 \pm 14.92)$. There was a statistically significant difference between the burden mean score before and after the intervention. 
Table (5): Quality of life Q1\& Q2 mean score of the studied caregivers before and after the psycho-educational interventnion $(\mathrm{n}=50)$ :

\begin{tabular}{|l|l|l|l|l|l|}
\hline QOL question & $\begin{array}{l}\text { Pre } \\
\text { Mean+SD }\end{array}$ & $\begin{array}{l}\text { Post (immediately) } \\
\text { Mean+SD }\end{array}$ & $\begin{array}{l}\text { Follow (2 month) } \\
\text { Mean+SD }\end{array}$ & F & P \\
\hline WHOQOL-1 & $1.88 \pm .69$ & $2.7 \pm 1.16$ & $2.23 \pm .89$ & 13.514 & .001 \\
\hline WHOQOL-2 & $2.5 \pm .65$ & $2.52 \pm .76$ & $2.5 \pm .68$ & 1.116 & .908 \\
\hline
\end{tabular}

Table (5): There was a statistically significant difference regarding WHOQOL question-1 $(\mathrm{P}=.001)$

Table (6): Quality of life domains' mean score of the studied caregivers before and after the psycho-educational intervention $(\mathrm{n}=50)$ :

\begin{tabular}{|l|l|l|l|l|l|}
\hline $\begin{array}{l}\text { Quality of life } \\
\text { Domains }\end{array}$ & $\begin{array}{l}\text { Pre } \\
\text { Mean+SD }\end{array}$ & $\begin{array}{l}\text { Post } \\
\text { (immediately) } \\
\text { Mean+SD }\end{array}$ & $\begin{array}{l}\text { Follow (2 } \\
\text { month) } \\
\text { Mean+SD }\end{array}$ & F & P \\
\hline Physical domain & $70.64 \pm 9.34$ & $78.48 \pm 9.83$ & $76.13 \pm 9.56$ & 13.289 & .002 \\
\hline $\begin{array}{l}\text { Psychological } \\
\text { domain }\end{array}$ & $44.32 \pm 12.80$ & $67.28 \pm 22.65$ & $59.33 \pm 16.23$ & 15.562 & .001 \\
\hline Social domain & $20.56 \pm 6.86$ & $33.84 \pm 14.68$ & $27.44 \pm 11.71$ & 15.108 & .001 \\
\hline $\begin{array}{l}\text { Environmental } \\
\text { domain }\end{array}$ & $57.60 \pm 11.90$ & $65.40 \pm 28.46$ & $65.63 \pm 19.01$ & 17.126 & .001 \\
\hline
\end{tabular}

Table (6): found an improvement in the quality of life domains immediately post the intervention in relation to physical, psychological, social and environmental domains. Concerning physical domain, the mean score of the studied caregivers pre-intervention was slightly lower (70.64+9.34). Immediately post-intervention, mean scores of the studied caregivers increased compared to pre-intervention (78.48+9.83).

In relation to psychological domain, the mean score of the studied caregivers pre-intervention was slightly lower (44.32 \pm 12.80$)$. Immediately post- intervention, mean scores of the studied caregivers increased compared to pre-intervention (67.28 22.65$)$. Speaking about social domain, the mean score of the studied caregivers preintervention was slightly lower (20.56+6.86). Immediately post-intervention, mean scores of the studied caregivers increased compared to pre-intervention $(33.84+14.68)$. Regarding environmental domain, the mean score of the studied caregivers pre-intervention was slightly lower (57.60+11.90). Immediately post intervention, mean scores for the studied caregivers increased compared to pre-intervention (65.40£28.46). There was a statistically significant difference between the quality of life domains mean score before and after the intervention.

Table (7): Correlation between burden mean score and total mean score of quality of life of the studied caregivers after the intervention $(\mathrm{n}=50)$ :

\begin{tabular}{|l|l|l|}
\hline \multirow{2}{*}{ Physical domain } & Total Burden post \\
\hline \multirow{2}{*}{ Psychological domain } & $\mathrm{r}$ & $-.331-$ \\
\cline { 2 - 3 } & $\mathrm{P}$ & .019 \\
\hline \multirow{2}{*}{ Social domain } & $\mathrm{r}$ & $-.756-$ \\
\cline { 2 - 3 } & $\mathrm{P}$ & .000 \\
\hline \multirow{2}{*}{ Environmental domain } & $\mathrm{r}$ & $-.754-$ \\
\cline { 2 - 3 } & $\mathrm{P}$ & .000 \\
\cline { 2 - 3 } & $\mathrm{r}$ & $-.835-$ \\
\hline
\end{tabular}

Table(7): found a negative correlation between quality of life domains mean score and the total burden mean score after the intervention with statistically significant relation.

\section{Discussion:}

Schizophrenia is a distressing mental disorder that is a main cause of suffering for patients. It also affects the performance and wellbeing of family caregivers, mainly because the caregivers have performed functions that were previously performed by Psychiatric institutions. Furthermore, the negative experience of caregivers may affect their ability to care for the patients. Research on family caregivers' QoL is therefore of importance both for the caregivers themselves and indirectly for patients' health (Abdel-Aziz, Shaheen \& Abdel-kader., 2011). 
Research has shown that psycho-educational interventions for caregivers were designed to enhance their burden and QOL by reducing family environmental stress through educating families about the illness, communicating more effectively with the patient, improving problem solving skills, coping better with the illness and hence reducing re-hospitalizations (Prasko, Kristyna, latalova, \& Mainerova,., 2011). Therefore, this study aimed to determine the effect of the psycho- educational intervention on burden and quality of life among caregivers of schizophrenic patients.

The current study finding regarding the effect of the psycho-educational intervention on family caregiver burden showed a statistically significant difference between pre and post intervention mean scores and after two months follow up. The caregiver psycho-education in the current study revealed positive effects in decreasing caregiver burden immediately and two months after the intervention. This may be due to the application of the psycho-education intervention may help them to enhance their readiness to care for their patients. A psychoeducation in this study consisted of assessment, teaching, training, and evaluation. Teaching activities provided information about the nature of schizophrenia that included, definition, signs and symptoms, early signs of relapse, medication and side effects, and management of side effect too, accepting the patient's behavior and what the family is able to do, and thus generate a healthier relation within the family.

These findings are in agreement with Chien, (2008) who stated that, the findings of the psycho -education program were hopeful and indicated a significant reduction in family burden related to daily life activities, relations with patient, and mental health members. In addition, there has been an enhancement in all domains of family performance, such as interpersonal relationship, communication and problem-solving skills.

Also, the results of the current study are congruent with previous research findings indicated that the psychoeducational program for family caregivers of schizophrenic patients lead to better acceptance of the disorder, and improved capacity to adapt to the role of caregiving (Sharif, Mahmoudi, Alavi \& Vossoughi, 2016). Moreover, Fallahi et al, $2014^{(5)}$ found that shared assistance groups for family caregivers of the psychiatric disorder provide a chance to the caregivers to share their caregiving problems with other caregivers. Also, other research has mentioned that the interactions between caregivers in groups may lead to useful assistance such as sharing experiences and emotional support which extended beyond the intervention time (Glick, Stekoll, \& Hays, 2011).

Maldonado \& Uri'zar, (2008) added that, caregivers psycho-educational intervention is particularly efficient in reducing the negative effects resulted from offering care to the patient, and in reducing feelings of uncertainty, discomfort or rejection.

Zauszniewski, Bekhet \& Suresky, (2008) suggested that when caregivers of schizophrenic patients are able to improve their coping strategies, it is potential that burden will be reduced after several years. Similarly, Yildirim, Buzlu\& Hacıhasanoğlu, (2014) indicated that family intervention led to substantial gains in knowledge, increased confidence considering the role of the family in the treatment process, and reductions in relatives' stress. And, lastly, Berglund, Vahlne \& Edman (2003) suggested that behavior family therapy reduced the feeling of burden on the families of mentally ill patients.

However, these results are inconsistent with McDonell et al. (2003) who found no valuable effects of family education, as any psychological intervention needs financial supports, time, suitable services, and motivated and educated therapists. Also, González-Blanch et al. (2010) and Carrà et al., (2007) mentioned that a brief family psycho-education is not enough to decrease the family caregiver burden.

QOL is one of the most important issues of the families with psychiatric patients, especially those with schizophrenia. Actually, QOL is an personal's specific perception of life satisfaction, physical health, psychosocial health, and family health.

The Findings of the present study illustrated increased total mean score of question 1 and 2 and the four domains of QOL (psychological, physical, environmental and social) after the psycho-educational intervention immediately and after two months follow up with statistically significant difference between all quality of life domains score over time. This may be because giving information and support in addition to a willingness and motivation to learn for effectively coping with their patients and ability to deal with a significant amount of the caregiving roles and responsibilities. Also, it may be due to the improvement of the caregivers burden in which there is a negative correlation between the mean score of the caregivers burden and the mean score of the quality of life post the intervention as illustrated in table (7). i.e that caregivers with low level of burden reported improved quality of life.

These findings are consistent with The study by Sharif et al. (2016) found an improvement in caregiver's QoL owing to the family's understanding of strategies for coping with everyday caregiving difficulties, family awareness to the patient's symptoms and behaviors, and ability to deal with them.

In this respect, the study conducted in Egypt by Soliman, Mahdy \& Fouad, (2019) mentioned that there was statistically significant difference between the quality of life's four domains among caregivers who received psycho-education measured by the WHO QoL scale. With a higher score, number of relapses diminish, the need for hospitalization diminishes and the financial burden on caregivers diminishes too. In addition to, Katsuki et al. (2011) and Jeste et al. (2015) family psycho-education may improve emotional distress and caregiver burden and 
concerned with promoting psychological wellbeing related quality of life domain.

Moreover, the results conducted in Iran showed that family intervention could improve psychological welfare of the family members and could improve QOL in the participants immediately and one month after the intervention (Sharif et al. 2016).

Therefore, it could be said that caregiver psycho-educational intervention conducted in the present study could satisfy the many needs of those caregivers and will empower them to improve their burden and QOL.

\section{Conclusion}

To conclude, the current study revealed that burden and quality of life among caregivers of patients with schizophrenia improved significantly after the psycho-educational intervention.

\section{Recommendation}

All caregivers of patients with schizophrenia should be counseled and encouraged to participate in psychoeducational programs to understand unnecessary behavioral changes and to to improve their burden and quality of life. Longitudinal study using various methods, consisting of both controlled trials with long periods of follow-up of the group program not only improve the health status of family caregivers but also rehabilitate schizophrenic clients.

\section{References}

Abdel-Aziz, E., Shaheen, M., \& Abdel-kader, N. (2011). Impact of psycho educational program on burdens among family caregivers of schizophrenic patients, Mental Health Nursing, Faculty of Nursing, Cairo University, Cairo, Egypt, 7(12), 822-830.

Abdulkareem JY, Folorunsho TN, and Akinsola A. (2009). Caregiver burden among relatives of patients with schizophrenia in Katsina, Nigeria. South. Afr.J.Psychiatr.;15(2):43-7.

Ali, S. (2015). Relationship between caregiving burden and psychological health status of caregivers caring for older adults with cancer. Master thesis ,Mansoura university, faculty of nursing.

Berglund, N., Vahlne, J\& Edman, A. (2003). Family intervention in schizophrenia. Social P sychiatry Psychiatric Epidem iology, 38,116-121.

Breitborde, N.J., Moreno, F.A., Mai-Dixon, N., Peterson, R., Durst, L., \& Bernstein B. (2011). Multifamily group psycho-education and cognitive remediation for first-episode psychosis: a randomized controlled trial. Bio Med Central Psychiatry, 11, 9-15.

Carrà G, Montomoli C, Clerici M, Cazzullo CL (2007). Family interventions for schizophrenia in Italy: randomized controlled trial. Eur Arch Psychiatry Clin Neurosci 257:23.

Chien, W. (2008). Effectiveness of Psychoeducation and Mutual Support Group Program for Family Caregivers of Chinese People with Schizophrenia. The Open Nursing Journal, 2008 (2) 28-39.

Fallahi, K., Sheikhona, M., Rahgouy, A., Rahgozar, M., \& Sodagari, F. (2014). The effects of group psychoeducational programme on family burden in caregivers of Iranian patients with schizophrenia. Journal Psychiatric Mental Health Nursing, 21, 438- 446.

Glick, I.D., Stekoll, A.H., \& Hays, S. (2011).The role of the family and improvement in treatment maintenance, adherence, and outcome for schizophrenia. Journal of Clinical Psychopharmacology, 31, 82-5.

González-Blanch C, Martín-Muñoz V, Pardo-García G, Martínez-García O, Álvarez-Jiménez M, RodríguezSánchez JM, et al. (2010). Effects of family psychoeducation on expressed emotion and burden of care in first-episode psychosis: a prospective observational study. Span J Psychol 13:389-395.

Gurney, S. (2013).The person with a mental disorder. The art and science of mental health nursing. 3rd ed. Maidenhead: McGraw-Hill Education.

Gutiérrez-Maldonado, J., \& Caqueo-Urízar, A. (2007). Effectiveness of a psycho-educational intervention for reducing burden in latin american families of patients with schizophrenia. Quality of Life Research, 16(5), 739-747.)

Hjarthag, F., Helldin, L., Karilampi, U., \& Norlander, T. (2010). Illness-related components for the family burden of relatives to patients with psychotic illness. Psychiatry Epidemiology, (45), 275-283.

Jeste, D.V., Palmer, B.W., Rettew, D.C., \& Boardman, S. (2015). Positive psychiatry: its time has come. Journal Clinical Psychiatry, 76(6), 675-83.

Katsuki, F., Takeuchi, H., Konishi, M., Sasaki, M., Murase, Y., Naito, A.,.. Furukawa, T.A. (2011). Pre-post changes in psychosocial functioning among relatives of patients with depressive disorders after brief multifamily psycho-education: a pilot study. Bio Med Central Psychiatry, 11(56), 244-56.

Maldonado, J \& Uri'zar, A. (2008). Effectiveness of a psycho-educational intervention for reducing burden in latin american families of patients with schizophrenia. Qual Life Res, 16:739-747.

McDonell MG, Short RA, Berry CM, Dyck DG (2003). Burden in schizophrenia caregivers: impact of family psychoeducation and awareness of patient suicidality. Fam Process 42:91-103. 
Neena, SS. and Kamal, SJ.:(2010). Understanding family functioning and social support in unremitting schizophrenia: A study in India, Indian journal of psychiatry, Vol. 52, Issue: 2, PP. 145-149.

North, C., Pollio, D., Sachar, B., Hong, B., Inserberg, K., \& Bufe, G. (1998). The family as a caregiver: a group psychoeducation model for schizophrenia. American Journal of Psychiatry, 68(1), 39-46.)

Pitschel-Walz, G., Baüml, J., Bender, W., Engel, R., Wagner, M., \& Kissling, W. (2006). Psychoeducation and compliance in the treatment of schizophrenia: results of the Munich Psychosis Information Project study. J Clin Psychiatry, 67, 443-452.)

Prasko, J., Kristyna,V., latalova, K., \& Mainerova, B. (2011).psycho-education for psychotic patients. Center of Neuropsychiatric studies, 155(4), 385-396.

Rafiyah I, Sutharangsee W.(2011). Review: Burden on Family Caregivers Caring for Patients with Schizophrenia and Its Related Factors, Nurse Media Journal of Nursing, 1, 1, January 2011, $29-41$

Sharif, F., Mahmoudi, A., Alavi Shooshtari, A., \& Vossoughi, M. (2016). Effect of a psycho-educational intervention for family members on caregiver burdens and psychiatric symptoms in patients with schizophrenia in Shiraz, Iran. BMC Psychiatry, 4(3), 12:48.

Soliman E., Mahdy R. \& Fouad H.(2018). Impact of psychoeducation program on quality of life of schizophrenic patients and their caregivers. Egypt J Psychiatr, 39, 35-41. Available from: http://new.ejpsy.eg.net/text.asp?

Soliman, E., Mahdy, R., \& Fouad, H. (2019).Impact of psycho-education program on quality of life of schizophrenic patients and their caregivers. Psychiatry Department, Zagazig University, Zagazig, Egyptian journal of psychiatry, 39(1), 35- 41.

World Federation of Mental Health. (2010).Caring for the caregiver: Why your mental health matters when you are caring for others. Woodbridge VA: Available at: www.wfmh.org.

World Health Organization. (1997). The development of the World Health Organization quality of life assessment instrument(the WHOQOL). Quality of Life Assessment. International Perspectives. Heidelberg: Springer Verlag.

Yazici, E., Karabulut, U., Yildiz, M., Baskant, T., Eda, N., Çakir, U., \& Celaleddin, T. (2016):Burden on Caregivers of Patients with Schizophrenia and Related Factors. Turkish Association of Neuropsychiatry, 53, 96-101.

Yildirim, A Buzlu, S., Hacıhasanoğlu, R., Camcioğlu, T.H., Erdiman, S., \& Ekinci, M.(2014).The Effect of Family-to-Family Support Programs Provided for Families of Schizophrenic Patients on Information about Illness, Family Burden and Self-Efficacy. Turkish Journal of Psychiatry, 25(1), 31-7.

Zaretsky, A. E., Rizvi, S., \& Parikh, S. V. (2007). How well do psychosocial interventions work in schizophrenic disorder? The Canadian Journal of Psychiatry, 52 (1), 14-21.

Zarit, S. H., Reever, K. E., \& Bach-Peterson, J. (1980). Relatives of the impaired elderly: Correlates of feelings of burden. The Gerontologist, 20, 649-655.

Zauszniewski, J.A., Bekhet, A.K., \& Suresky, M.J. (2008). Factors associated with perceived burden, resourcefulness, and quality of life in female family members of adults with serious mental illness. Journal American Psychiatry Nurses Association, 14(2), 125-35. 